\title{
ERRATUM
}

\section{Erratum to: Response to selection, heritability and genetic correlations between body weight and body size in Pacific white shrimp, Litopenaeus vannamei*}

\author{
Farafidy ANDRIANTAHINA (安迪 $)^{1}$, LIU Xiaolin (刘小林) $)^{1, * *}$, HUANG Hao (黄皓) ${ }^{2}$, \\ XIANG Jianhai (相建海) $)^{3}$ \\ ${ }^{1}$ College of Animal Science and Technology, Northwest A \& F University, Shaanxi Key Laboratory of Molecular Biology for \\ Agriculture, Yangling 712100, China \\ ${ }^{2}$ Hainan Guangtai Ocean Breeding Company Limited, Haikou 570000, China \\ ${ }^{3}$ Experimental Marine Biology Laboratory, Institute of Oceanology, Chinese Academy of Sciences, Qingdao 266071, China
}

(C) Chinese Society for Oceanology and Limnology, Science Press, and Springer-Verlag Berlin Heidelberg 2012

\section{Erratum to: Chinese Journal of Oceanology and Limnology \\ Vol. 30 No. 2, P. 200-205, 2012 \\ http://dx.doi.org/10.1007/s00343-012-1066-2}

The original version of the title of this article unfortunately contained a mistake. The spelling of the [ZResponse] was incorrect. The title should read: Response to selection, heritability and genetic correlations between body weight and body size in Pacific white shrimp, Litopenaeus vannamei. The publishing companies apologize to the authors.

The online version of the original article can be found at http://dx.doi.org/10.1007/s00343-012-1066-2. 